
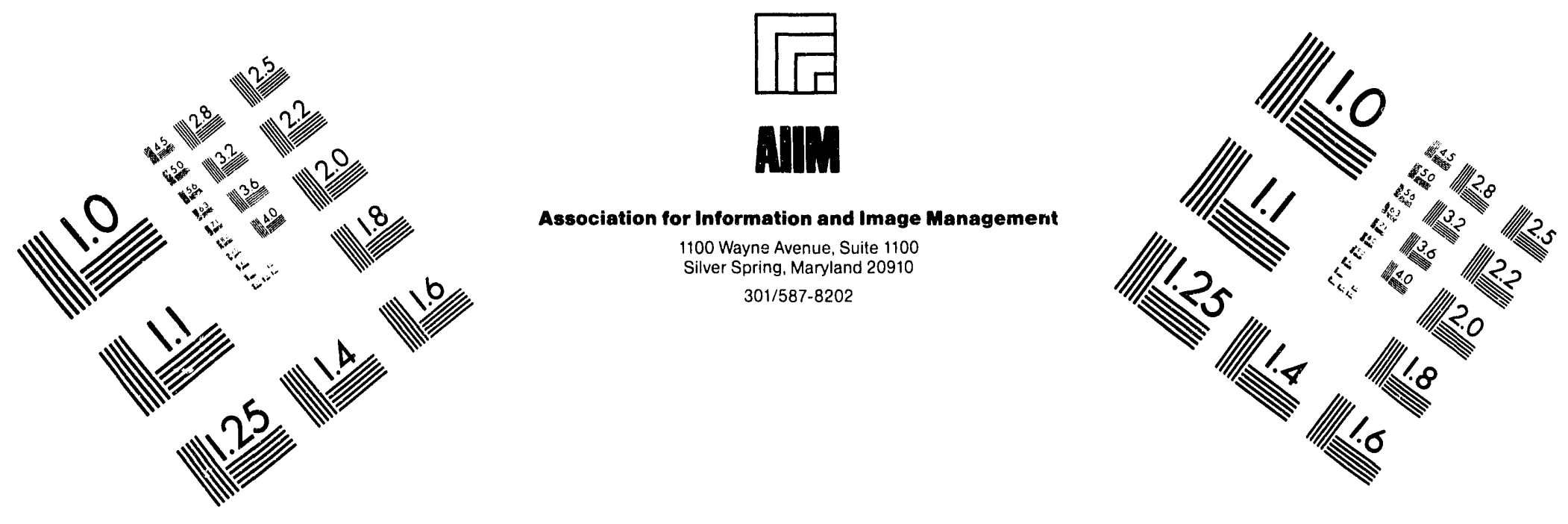

\title{
Centimeter
}

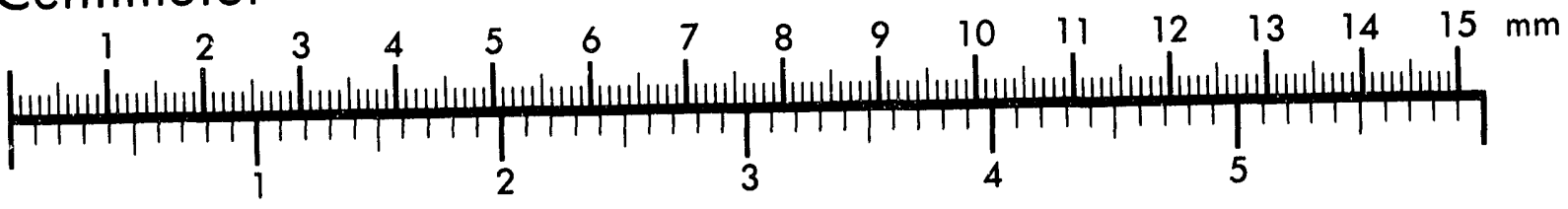
Inches
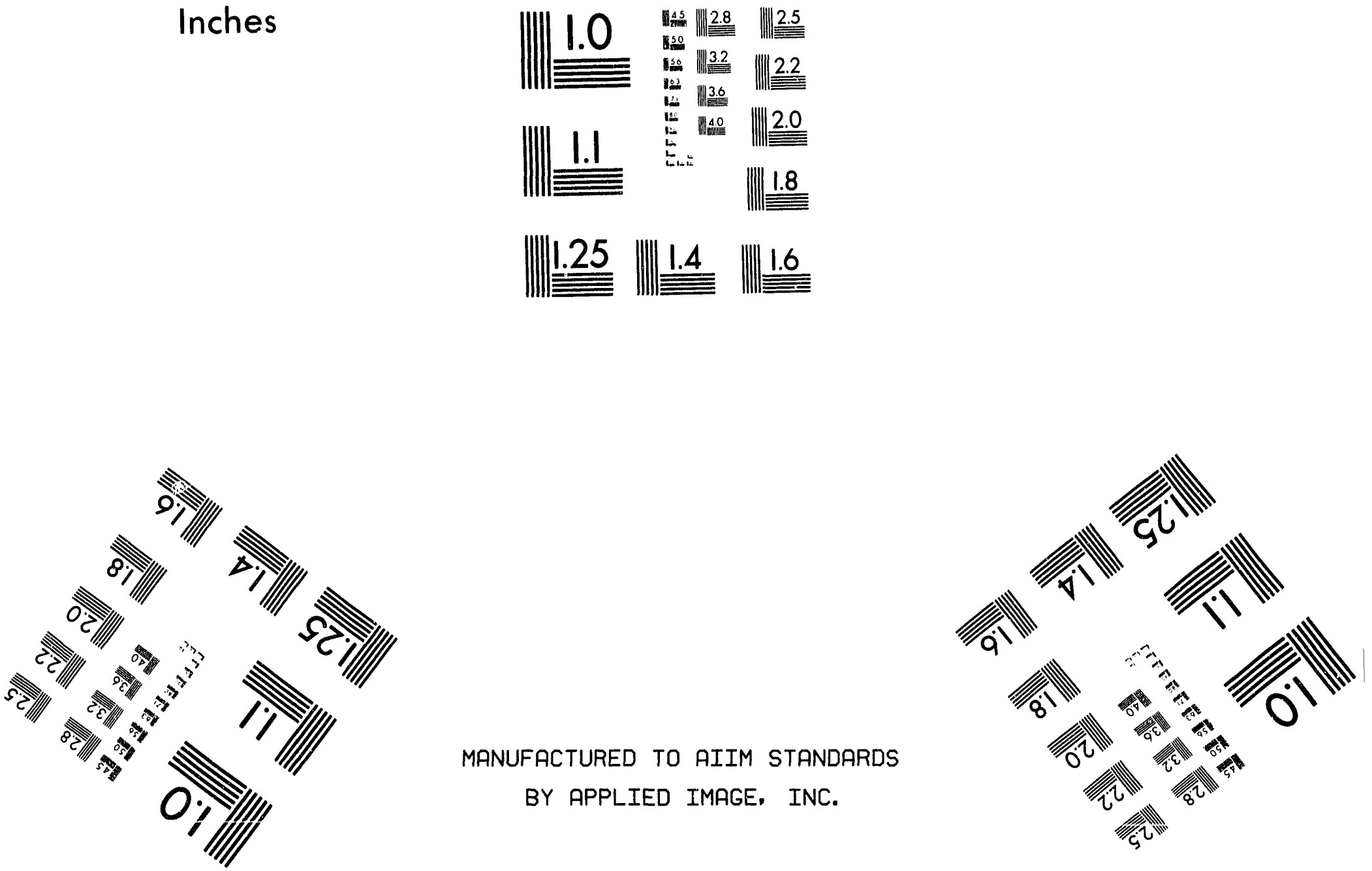

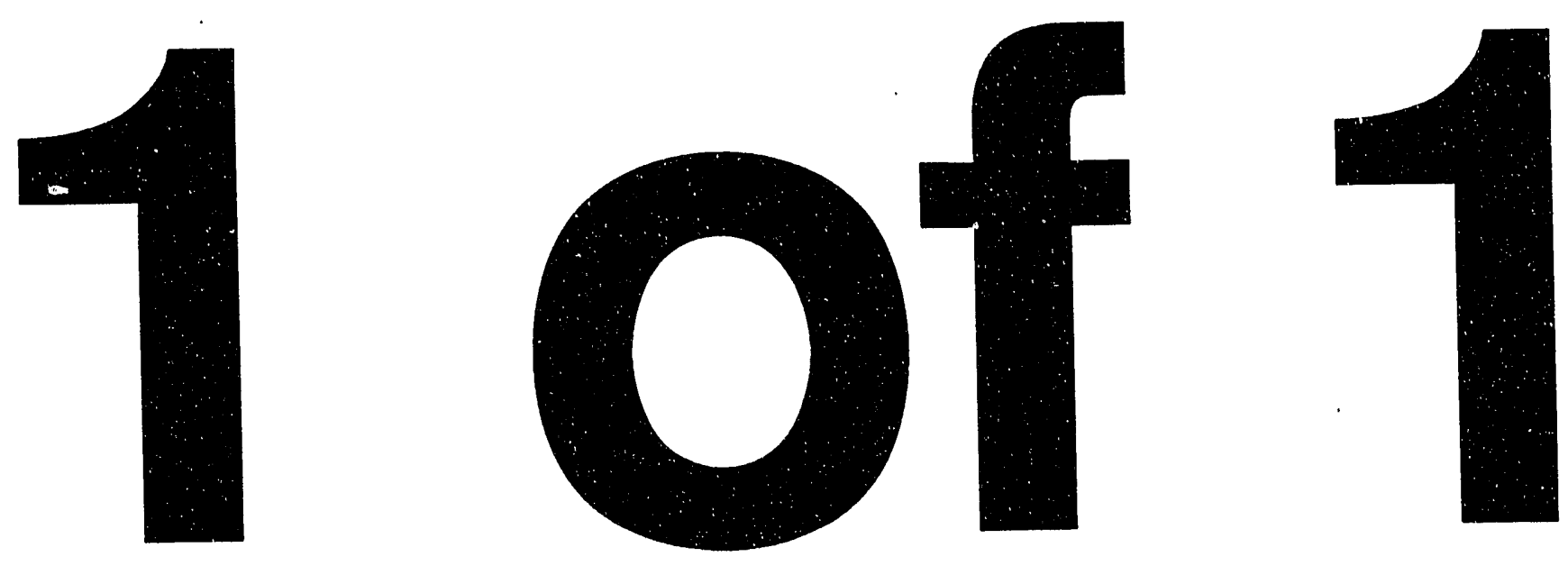
Presented at the Fourth International Industrial Symposium on

Super Collider (IISSC) in New Orleans, Louisiana, March 4-6, 1992

\section{AXIAL VARIATIONS IN THE MAGNETIC FIELD OF SUPERCONDUCTING DIPOLES *}

\author{
A. K. Ghosh, K. E. Robins and W. B. Sampson \\ Brookhaven National Laboratory \\ Upton, New York 11973
}

\section{ABSTRACT}

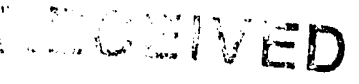

JUN 021933

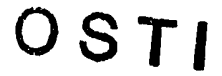

Periodic variations in the field along the axis have been observed in a large number of superconducting dipoles. Both long and short versions of the SSC magnet have been examined as well as prototypes for the RHIC accelerator and coils from the CBA and ISABELLE projects. This field oscillation is present in all the components of the field. The period of the longitudinal pattern was found to match the conductor transposition length over a wide range of pitches. The amplitude of variation increases with time spent at high field and its decay has a complex time dependance. Unbalanced currents in the individual strands of the cable appear to be the cause of this effect and may also give rise to the unusually high sextupole drift observed near injection field in most dipoles.

\section{INTRODUCTION}

When a superconducting accelerator magnet made from multistranded conductor (cable or braid) is energized an axial variation in the magnetic field is established which has the wavelength of the conductor transposition pitch. This pattern is present at all fields and in both the normal and skew components. The magnitude of this oscillation increases with both the maximum field achieved during the energizing cycle and the time spent at high field. This phenomenon was first observed in HERA dipoles in 1990 using a magnetic measuring device sensitive to the sextupole harmonic. The purpose of this probe was to study the anomalous sextupole drift which occurs when the magnet is at the injection field. It was noticed that small axial changes in the position of the probe produced large changes in the field and the unusual systematic variation discovered. Further investigation revealed that the variation was approximately sinusoidal and that its amplitude increased each time the magnet was cycled to high field. Similar variations were soon observed at other laboratories and it became apparent that such patterns were present in all magnets made with cabled conductors. This field oscillation had not been seen earlier with more conventional

DISTRIBUTION OF THIS DOCUMENT IS UNLIMITED

$\bar{*}$ Work done under the auspices of the U. S. Department of Energy

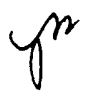




\section{MAGNETS MEASURED}

Superconducting dipoles for accelerator applications have been under development at BNL for many years making it possible to compare magnets made from a variety of conductors. To date some fifteen dipoles have been examined. They are listed in Table I. Ten of these magnets are SSC prototypes of 4 or $5 \mathrm{~cm}$ design and include both short and full-length versions. All magnets examined so far have shown axial patterns in their remnant field and the wavelength of the variation has coincided exactly with the transposition length of the inner cable. In cases where the pitch of the axial field pattern was not precisely equal to the nominal transposition iength, direct measurement of the cable showed exact agreement. A typical pattern of the remnant dipole field is shown in Figure 1 for RHIC short magnet DRS006.

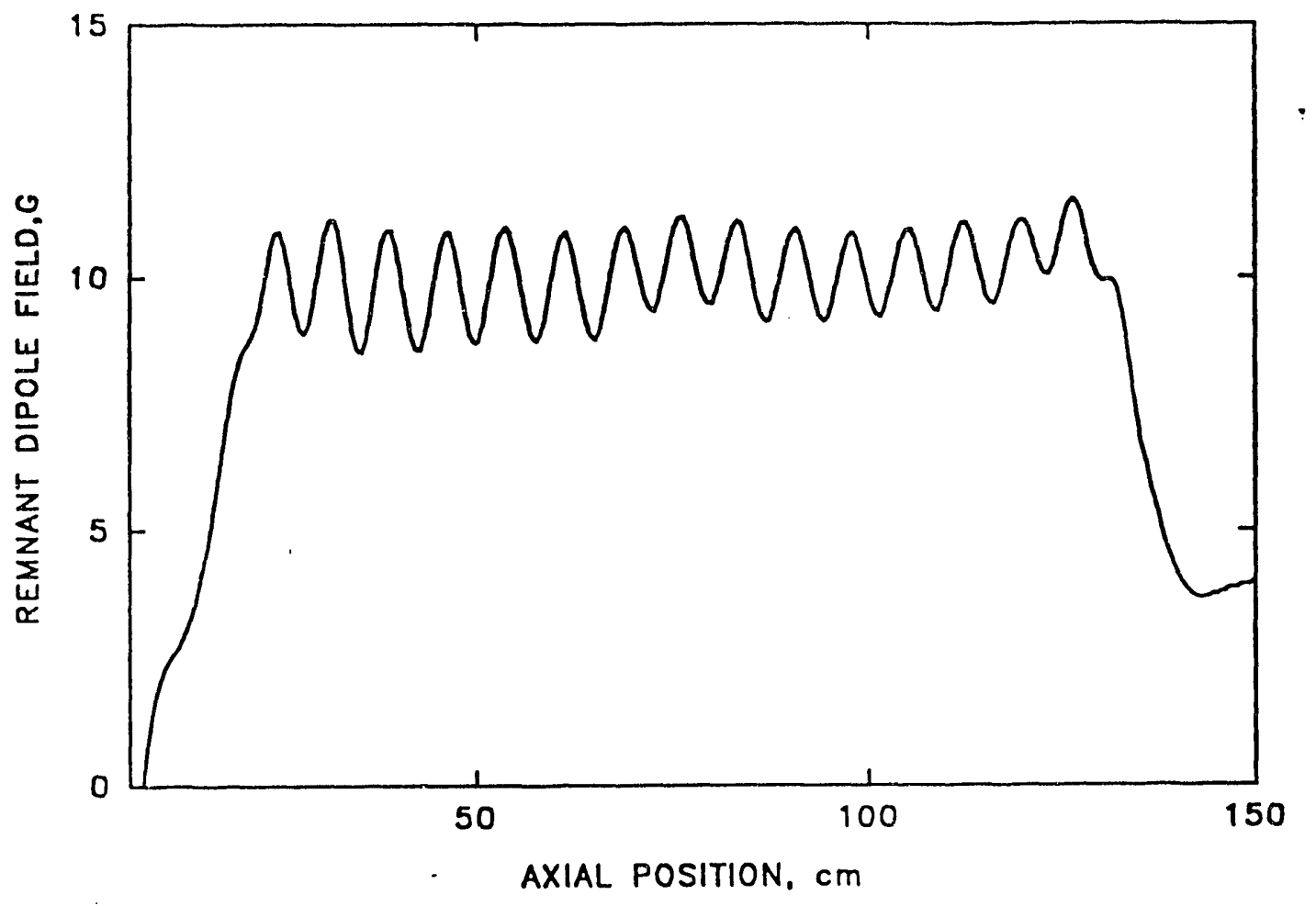

Figure 1. Axial scan of the remnant dipole field in magnet DRS006 after a 30 minute flat-top at 7000 Amps.

Since Rutherford cable is basically a flattened spiral there were early suspicions that the effect was related to the solenoidal path followed by the strand currents. To test this idea a magnet made from braided conductor which has strands spiraling in both directions, was examined. The field oscillations in this magnet were obvious and coincided with the very long $(316 \mathrm{~mm})$ transposition length of the braided conductor.

The possibility that this phenomenon is caused by filament deformation resulting from the cable manufacturing process was tested using a dipole made with $\mathrm{Nb}_{3} \mathrm{Sn}$ cable. The filaments are formed by heat treatment after cabling so that any edge degradation should be minimized. Again the axial field pattern was obvious suggesting that any conductor made from multiple strands would give rise to field oscillations. 


\section{OSCILLATION AMPLITUDE}

As mentioned above the axial oscillations only appear when a magnet has been held at high field for some time. For a given field level the amplitude grows exponentially with time much like the voltage on a charging capacitor. The charge-up time constant is typically $500 \mathrm{sec}$. but in one case was observed to be well over ten thousand seconds. Similarly the maximum amplitude varies considerably from magnet to magnet. The largest peak-to-peak amplitude measured to date is approximately 10 Gauss whereas the smallest is less than 1 Gauss. Determining the charge up time constant in a magnet with a high decay rate can be complicated by the fact that amplitude decay begins as soon as the coil leaves the flat top and considerable time can elapse before the field is low enough to accurately measure the amplitude. At the present time there is no explanation of these large differences in signal strength and charge time but it has been speculated that the magnitude of the effect depends on the uniformity of the individual strands in the cable. This is based on the fact that a magnet made from a cable which had been fabricated from a single length of wire was observed to have very small oscillations which required many hours of flat top time to grow to measurable size.

The situation can in some cases be much more complicated than outlined above. One of the SSC model magnets DSO206 exhibited the unusually behavior shown in Figure 3. When energized to 6700 amps for $30 \mathrm{~min}$. the axial scan revealed almost

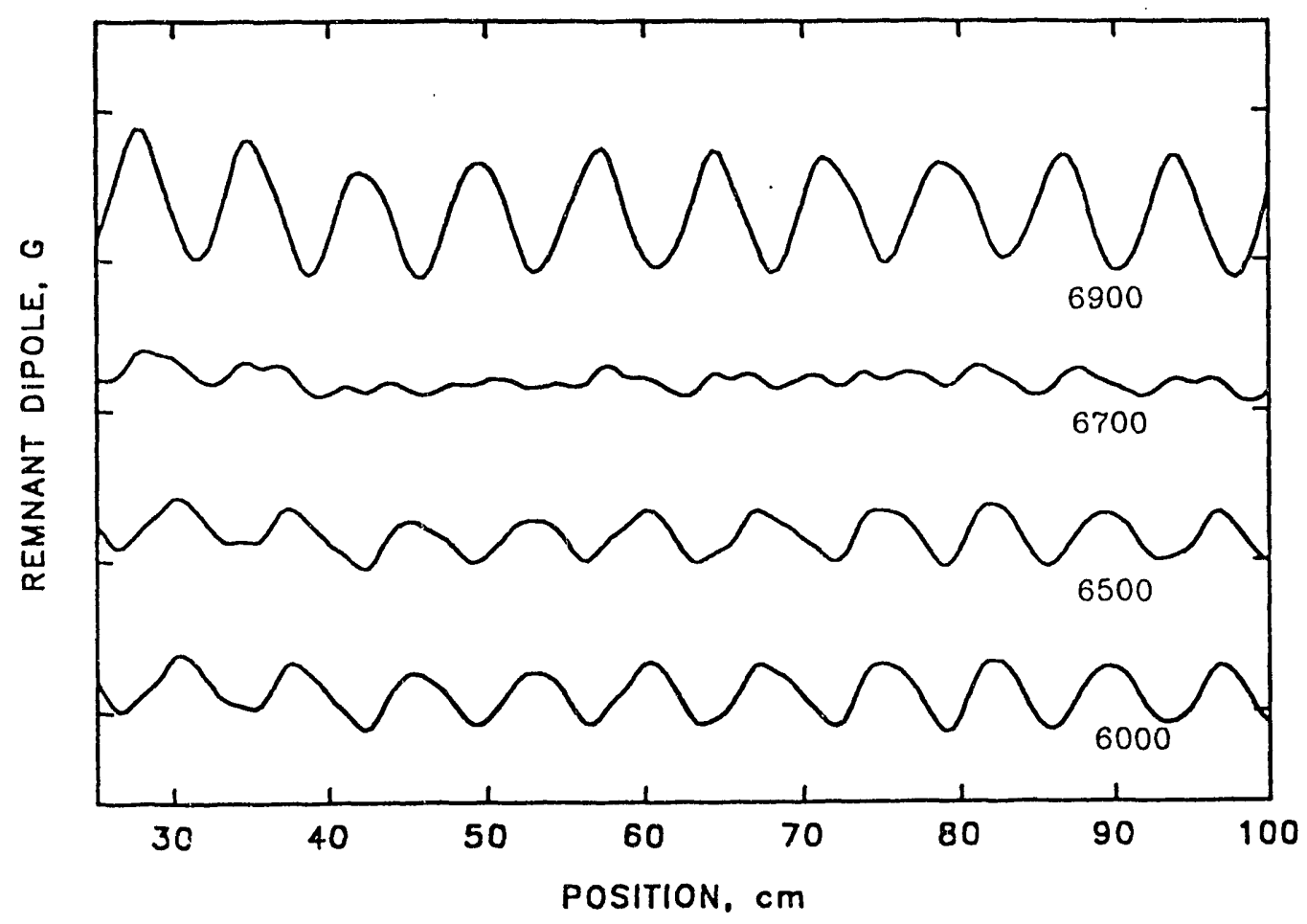

Figure 3. Axial pattern in the remnant dipole field of magnet DS0206 after successive cycles to currents near 6700 Amps.

none of the usual structure but at currents 200 amps more or less that this value the characteristic pattern shows distinctly. The patterns for different currents have been offset vertically in Figure 3 for clarity. Note that the phase in the axial direction 


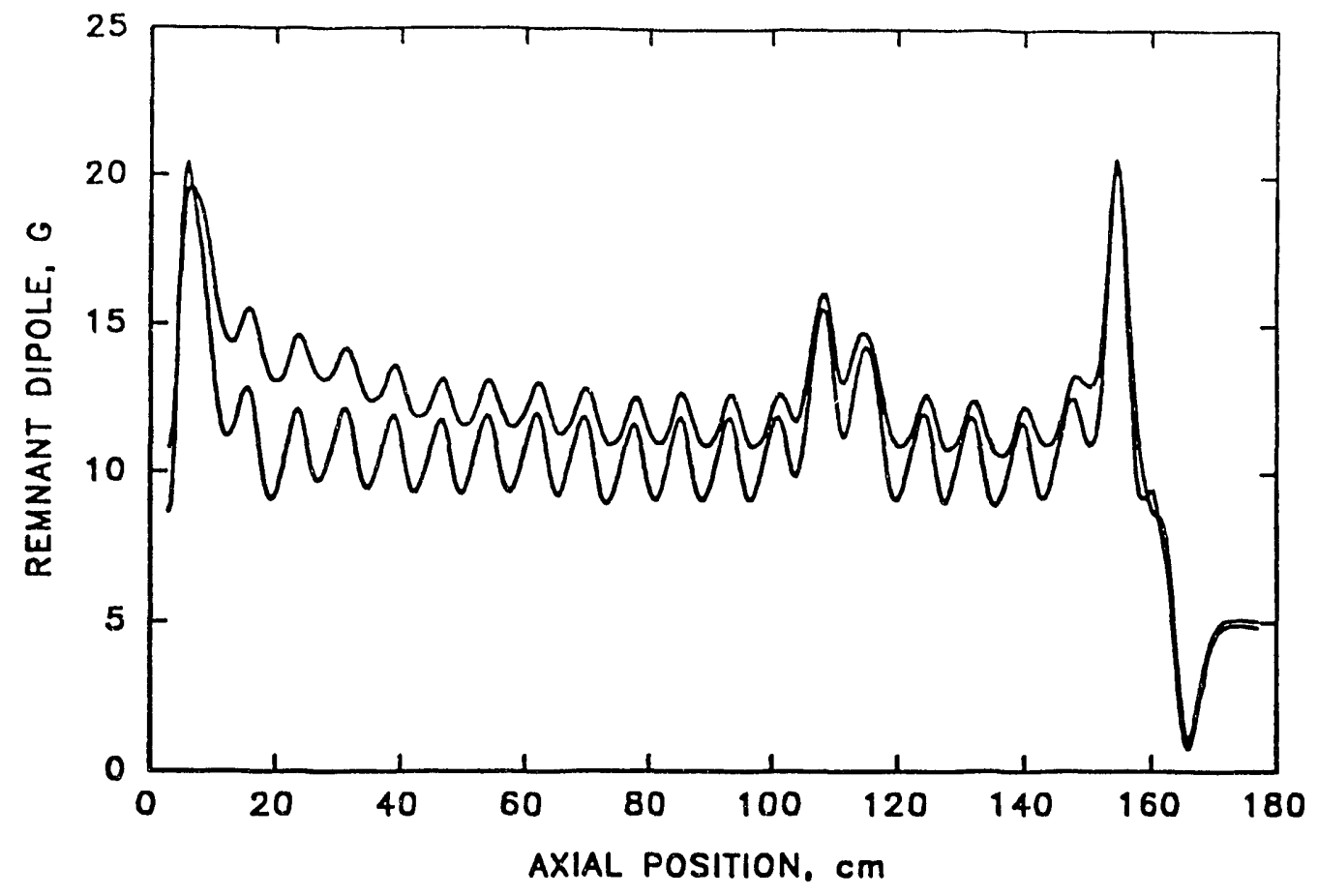

Figure 5. Axial scans in magnet DSKR19 before and after energizing the inner lead heaters. The hump at approximately $110 \mathrm{~cm}$ is caused by the strain gauge holder.

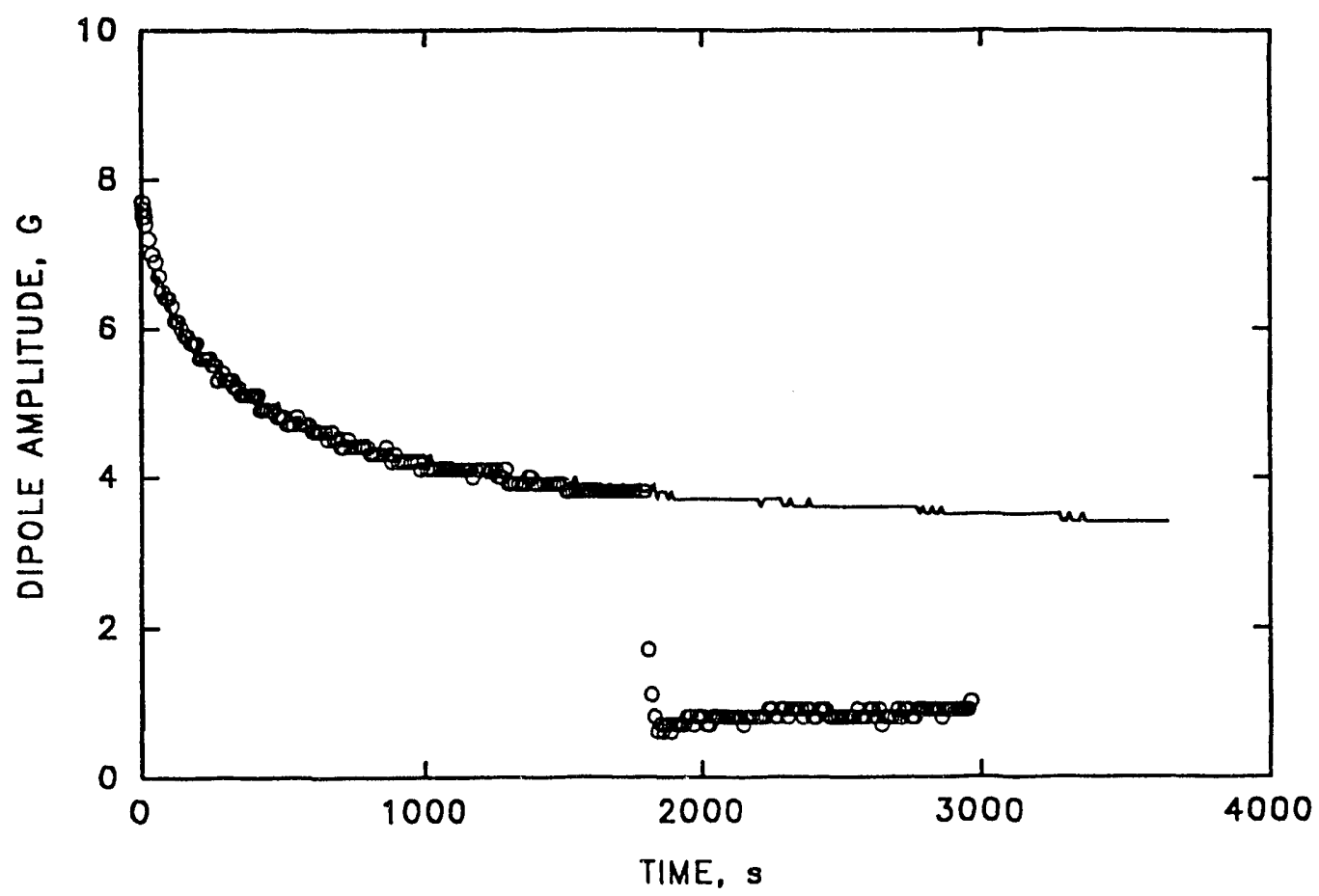

Figure 6. Time dependance of the dipole oscillation amplitude showing the effect of heater power. The solid curve is the decay after a cycle to 6700 . The points are the same cycle with heater power applied at 1800 seconds. 


\section{DISCLAIMER}

This report was prepared as an account of work sponsored by an agency of the United States Government. Neither the United States Government nor any agency thereof, nor any of their employees, makes any warranty, express or implied, or assumes any legal liability or responsibility for the accuracy, completeness, or usefulness of any information, apparatus, product, or process disclosed, or represents that its use would not infringe privately owned rights. Reference herein to any specific commercial product, process, or service by trade name, trademark, manufacturer, or otherwise does not necessarily constitute or imply its endorsement, recommendation, or favoring by the United States Government or any agency thereof. The views and opinions of authors expressed herein do not necessarily state or reflect those of the United States Government or any agency thereof. 

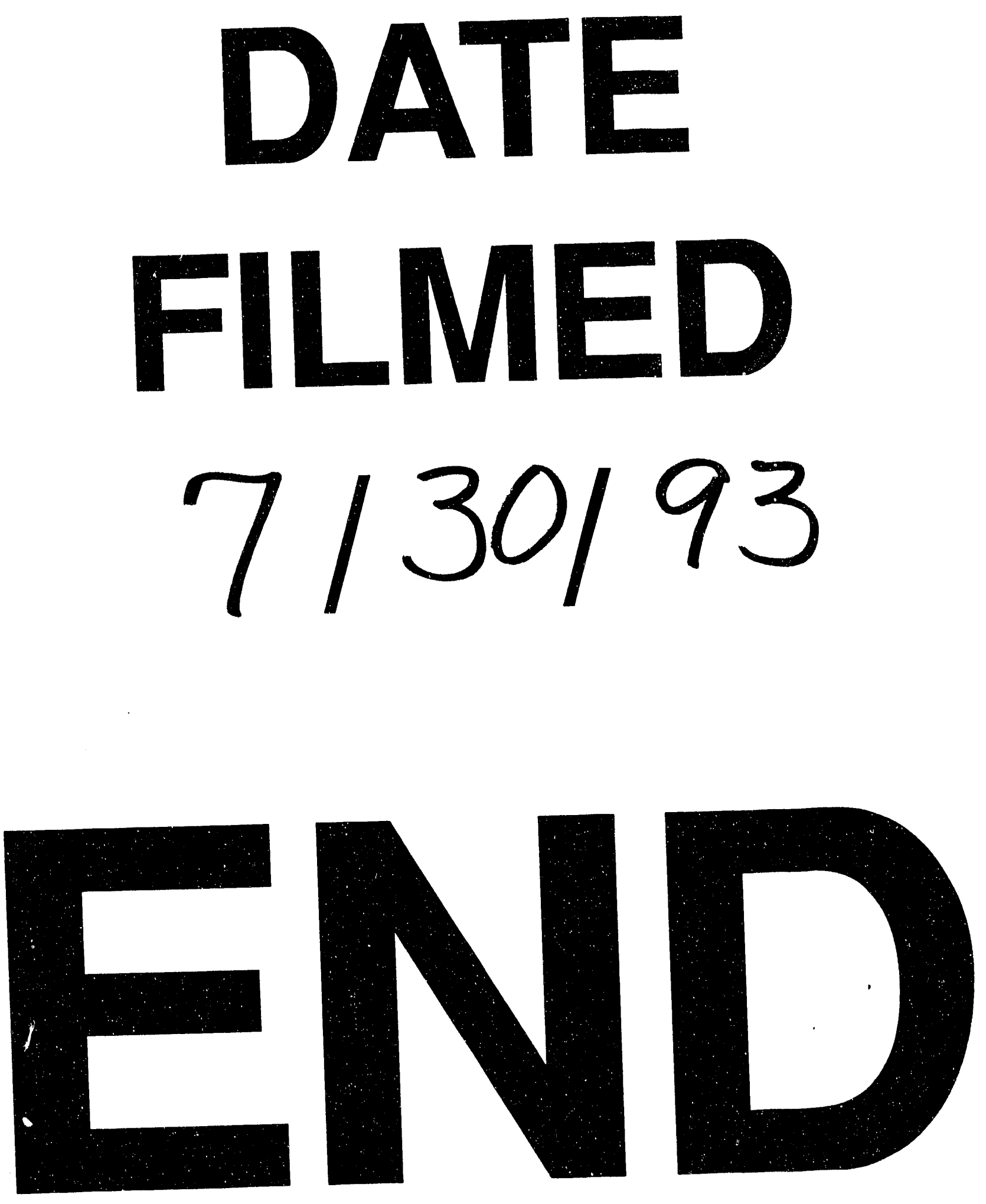
